\title{
Perfil de drogadição e práticas sociais entre moradores de rua ${ }^{1}$
}

\author{
Addiction profile and social practices among homeless people
}

\author{
Lila Spadoni \\ Cilas Pereira Machado Júnior ${ }^{3}$ \\ Letícia Houston Mamede Barroso ${ }^{4}$ \\ Ana Luiza Boni ${ }^{5}$ \\ Margareth Regina Gomes Veríssimo de Faria ${ }^{6}$ \\ Sandra Maria Brunini de Souza ${ }^{7}$
}

\begin{abstract}
RESUMO: Este artigo apresenta dados que indicam a existência de três grupos sociais entre os moradores de rua: os alcoolistas, os adictos de crack e os polidrogaditos. Para isto, utiliza-se do arcabouço teórico e metodológico da abordagem estruturalista das representações sociais para demonstrar que cada grupo é reconhecido entre os moradores de rua como tendo um perfil de práticas. A amostra é composta por uma população de internos de uma instituição não governamental, que se dedica exclusivamente ao cuidado dessa população. Os resultados indicam diferenças entre os alcoolistas e usuários de crack ou polidrogaditos.
\end{abstract}

Palavras-chave: moradores de rua; representações sociais; drogadição.

ABSTRACT: This article presents data indicating the existence of three social groups among the homeless: alcoholics, crack addicts and multiple drug users. For this, it uses the theoretical and methodological framework of the structuralist approach of social representations to demonstrate that each group is recognized among the homeless as having a conduit profile. The sample consists of mens who are into a non-governmental organization dedicated exclusively to the care of this population. The results indicate some differences between alcoholics and crack or multiple drugs users.

Keywords: homeless, social representations, drougs addiction.

\section{Introdução}

As políticas públicas a respeito da drogadição no Brasil passou, a partir do final da década de 2000, a considerar as casas de recuperação de cunho religioso como uma opção

\footnotetext{
${ }^{1}$ Os acadêmicos autores deste artigo contaram com Bolsa de Iniciação Científica do PIBICICNPQ e FUNADESP.

2 Doutora em Psicologia pela Universidade Paris 5. Professora Titular do Centro Universitário de Anápolis. Professora Assistente do Programa de Pós-graduação em Educação da Pontifícia Universidade Católica de Goiás - Goiânia, GO, Brasil. Email: lilaspadoni@gmail.com.

${ }^{3}$ Residente de Medicina no Centro Universitário de Anápolis - Anápolis, GO, Brasil.

${ }^{4}$ Graduanda de Psicologia no Centro Universitário de Anápolis - Anápolis, GO, Brasil.

${ }^{5}$ Graduanda de Psicologia no Centro Universitário de Anápolis - Anápolis, GO, Brasil.

${ }^{6}$ Doutora em Psicologia pela Universidade Católica de Goiás. Professora Adjunta do Centro Universitário de Anápolis. Professora Assistente da Pontifícia Universidade Católica de Goiás - Goiânia, GO, Brasil.

7 Doutora em Enfermagem pela Universidade de São Paulo (USP). Professora Titular do Programa de Pós-graduação em Enfermagem da Universidade Federal de Goiás - Goiânia, GO, Brasil.
} 
de tratamento, reconhecendo o serviço que vinha sendo prestado por estes estabelecimentos durante décadas.

Poucas casas de recuperação trabalham exclusivamente com o morador de rua. No centro-oeste brasileiro, há 25 anos, foi fundada uma casa de recuperação que se dedica exclusivamente a essa população. Em 2013, uma equipe de alunos e pesquisadores da Universidade Federal de Goiás e do Centro Universitário de Anápolis iniciaram um trabalho de extensão e pesquisa nessa instituição.

Em sondagem inicial percebeu-se que o médico, clínico geral da instituição, havia feito observações e registros que indicavam uma transformação no perfil de drogaditos, sendo possível identificar entre os internos, aqueles que se afirmam como dependentes de álcool, que se diferenciam dos dependentes de crack e/ou de outros derivados da cocaína. Essa observação foi tomada como hipótese para o estudo que será apresentado neste artigo.

A partir de 2004, o Ministério do Desenvolvimento Social e Combate à Fome (MDS) inclui em sua agenda a formulação de políticas públicas voltadas especificamente para a população em situação de rua. Como resultado desta agenda, em dezembro de 2009, foi instituída a Política Nacional para a "população em situação de rua" e a criação de um Comitê Intersetorial de Acompanhamento e Monitoramento deste grupo populacional.

No entanto, historicamente, o cuidado às pessoas em situação de rua esteve fortemente relacionado a organizações não governamentais (ONGs) tais como igrejas, movimentos religiosos ou organizações civis filantrópicas. Ou ainda, organizações governamentais municipais por iniciativa de prefeitos ou secretários municipais, sem que isso constituísse uma política governamental.

A partir do momento que essa população passou a ser alvo das políticas públicas, fomentou-se também o número de investigações científicas que possam orientar as ações em favor dessa população. Segundo Pousa Junior (2011), nos últimos anos aumentou o número de investigações, envolvendo essa população e permitindo o desenvolvimento de novos conceitos e metodologias que efetivamente mensuram e aprofundam o conhecimento desse grupo social. Porém, muitas pesquisas ainda são necessárias para a melhor compreensão dessa população, seus determinantes, suas necessidades e quais as políticas públicas que devem estar envolvidas para minorar o sofrimento destas pessoas (Ferreira, 2005).

O levantamento feito pela secretaria de assistência social de São Paulo mostrou que o número de pessoas em situação de rua tem aumentado nos últimos anos, o que é mostrado pelos registros de 3.392 pessoas em 1991 que cresce paulatinamente chegando a totalizar 15.905 em 2015 (São Paulo, 2015).

O crescimento dessa população é preocupante, pois ela possui características que revelam uma vulnerabilidade extrema, que ultrapassa às demais condições que classicamente definem baixas condições sócioeconômicas na população em geral. O viver na rua, e a insegurança causada pela falta de moradia, constituem fatores que levam a situações de maior exposição às doenças, a violência e a falta de acesso aos serviços (Varanda \& Adorno, 2004).

O uso do álcool e outras drogas fazem parte da realidade das ruas, seja como uma forma de minimizar a fome e o frio, seja como uma forma de socialização entre os membros 
dos grupos. O uso dessas substâncias é considerado há muito tempo como uma das dimensões culturais que compõem o estilo de vida da população em situação de rua (Costa, 2005; Snow \& Anderson, 1998).

É raro encontrar um morador de rua que não seja drogadito, no entanto, é difícil dizer qual situação foi o início dessa condição. Ou seja, é difícil afirmar se foi a drogadição que levou o indivíduo a viver nas ruas, ou se foi a condição de rua que levou o indivíduo a drogadição. Outras vezes, entretanto, a drogadição surge, simultaneamente, como condição e efeito da "rualização" (Mattos, Campos \& Ferreira, 2004). Por isso Vieira (1995) destaca que o uso de drogas enraíza a pessoa na situação de rua, reduzindo, muitas vezes, as chances de saída da mesma.

O uso do álcool é reconhecido como fator de fragilização da saúde dos indivíduos moradores de rua, entre eles a suscetibilidade maior a outras enfermidades, a redução da possibilidade de engajamento em trabalhos fixos, o esgotamento físico e acidentes (Botti et al., 2013; Lovisi, 2000). O alcoolismo é uma condição bem conhecida entre os moradores de rua, ao contrário do crack, que começou a ser utilizado no final dos anos 80 , inclusive por crianças e adolescentes (Noto et al., 2003). Além de apresentarem-se como um agravante por si só, o consumo de cocaína e crack têm sido diretamente associados à infecção pelo HIV (Pechansky et al., 2002; Cruza, Vargens \& Ramoac, 2010).

Além disso, práticas relacionados ao compartilhamento de seringas e cachimbos, atividade sexual com múltiplos parceiros e sem preservativos, inclusive como forma de conseguir dinheiro para comprar as drogas, são práticas normalmente adotadas que predispõem essa população à infecção por hepatite $B$ e $C$ e outras doenças sexualmente transmissíveis (Booth, Kwiatkowski \& Chitwood, 2000; Duailibi, Ribeiro \& Laranjeira, 2013).

Atualmente a política de redução de danos tem sido adotada em vários países, inclusive o Brasil. A redução de danos propõe práticas educativas que devem ser pautadas na realidade do sujeito, visando sua emancipação e a adoção de um estilo de vida mais saudável, mesmo com o uso da droga. Segundo Figueiredo (2002, p. 9): "Essa abordagem incluiu, conforme novos pressupostos educacionais, as vivências e experiências dos sujeitos em questão, suas condutas e códigos de comunicação, motivando a sua capacidade de compreender, decidir e abordar a questão, fortalecendo a reflexão e a autonomia individual."

Por isso, pensamos que seja profícuo conhecer as práticas sociais que são normatizadas entre os moradores de rua, levando em consideração que existem diferentes grupos sociais entre eles, onde circulam representações sociais também diferentes. Neste estudo, propomos investigar a hipótese de que há atualmente três grupos sociais que compõem a população de moradores de rua: o grupo dos que se consideram alcoolistas, dos que se consideram viciados em crack e dos polidrogaditos. Isso significa que cada grupo tem suas características específicas e também peculiaridades em sua cultura.

\section{Normas, práticas e estrutura das representações sociais}

Essa pesquisa tem como fio condutor as teorias da psicologia social europeia, mais especificamente, a abordagem das representações sociais (Moscovici, 1978), considerada 
numa perspectiva ampla. Isso significa que, embora não seja um estudo clássico sobre representações sociais, utiliza pressupostos dessa abordagem, que passamos a descrever.

A teoria das representações sociais atualmente não se restringe apenas as representações, mas considera uma articulação de diversos conceitos da psicologia social tais como normas, valores, práticas, atitudes e opiniões.

Esses conceitos têm sido reunidos e organizados sob a nomenclatura "pensamento social". O senso comum pode ser visto pela psicologia positivista como um conhecimento irracional e enviesado, mas para os teóricos das representações sociais, essa forma de pensamento possui uma coerência própria, arraigada na articulação entre a cognição, a comunicação e a socialização (Rouquette, 1973).

Para Rouquette (2009) desmerecer a lógica do pensamento social equivale a se opor a existência de um sujeito cidadão, prático, que tem suas atividades cognitivas condicionadas às peculiaridades de sua inserção social. Este tipo de pensamento não possui apenas uma lógica própria, mas é também estruturado, organizado dentro de uma hierarquia que deve ser investigada a partir das propriedades formais da ciência. Por isso, Rouquette propõe uma arquitetura do pensamento social, na qual ele organiza numa hierarquia de quatro níveis, a integração dos principais conceitos que a compõem.

O nível superior é caracterizado por uma inércia própria das ideologias, no qual se organizam as crenças, os valores e as normas. Esse nível é difícil de ser mudado pois ele garante uma certa estabilidade ao pensamento social, ao contrário dos demais níveis que proporcionam uma instabilidade abarcando as mudanças.

Nesse nível superior se localizam as normas que são responsáveis por prescrever as práticas sociais adotadas pelos grupos. Esse tema nos interessa neste artigo porque investigamos as normas de conduta que definem as práticas que são aceitas pelos moradores de rua, sendo que algumas são consideradas inaceitáveis para outros grupos sociais. São normas que prescrevem os comportamentos que podem ser considerados como crimes pela legislação brasileira tais como roubar e traficar e que nomeamos, neste estudo, de práticas antinormativas.

As práticas fazem parte das representações sociais. Como afirma Jodelet (1989, p. 86), as representações sociais são uma forma de conhecimento, socialmente elaborado e partilhado, com um lado prático que contribui para a construção de uma realidade comum a um grupo social.

Nos níveis mais inferiores da arquitetura do pensamento social estão as opiniões e atitudes, que se caracterizam por serem mais instáveis e variáveis. A respeito das mesmas normas sociais, os membros do grupo podem ter várias opiniões e atitudes, e podem ainda mudá-las com certa frequência. As representações sociais se localizam no nível intermediário dessa arquitetura, pois ela concilia a estabilidade e a instabilidade, o durável e o efêmero, o consenso e o dissenso.

De um ponto de vista estrutural, a representação social possui um sistema central que assegura a sua estabilidade e consenso. O sistema central é composto por elementos que dão significado a representação sendo que as normas, que prescrevem as práticas aceitas fazem parte desse sistema. As normas, portanto, contribuem para estruturar o significado 
do conhecimento social e concorre para a construção de visão de mundo das pessoas, prescrevendo práticas (Abric, 1994).

O sistema periférico das representações sociais, por sua vez, tem a função de proteger o sistema central adaptando a representação às circunstâncias, amortecendo as o impacto das mudanças e das discordâncias (Abric, 1994).

Nesse sentido, essa pesquisa adota a ideia de que os grupos sociais possuem crenças, normas, valores e representações que os caracterizam, pois são compartilhadas entre os membros do grupo. Os moradores de rua formam um grupo social que se caracteriza por compartilhar todas essas formas de pensamento social, que compõem uma cultura deles.

Temos a hipótese que eles se diferenciam, dentro desta cultura, pelo tipo de drogadição e que, portanto, reconhecem diferenças entre os alcoolistas e os dependentes de crack e demais drogaditos.

Essa pesquisa considera o senso comum como seu objeto, visto que não procura verificar os fatos em si, mas procura conhecer o que os moradores de rua afirmam sobre os fatos. Ou seja, procura identificar aquilo que circula nas conversações ordinárias entre eles, especialmente suas crenças sobre a influência do tipo de drogadição em seus comportamentos.

\section{Método}

Pesquisa de campo, do tipo survey, através de questionários. Os participantes são internos de uma instituição filantrópica fundada em Anápolis, no ano de 1983, que trabalha na recuperação de pessoas em situação de rua. Os participantes foram abordados durante o período de internação em horários livres.

\section{Participantes}

A amostra foi composta por 94 participantes que se encontravam internados na instituição de recuperação.

Com relação à faixa etária dos participantes, as idades foram agrupadas em intervalos de 19 a 29, 30 a 39, 40 a 49, 50 a 59 e acima de 60 anos. A faixa mais prevalente foi de 30 a 39 anos, com 41 pessoas. Nesse grupo, as idades de 30 e 34 anos representaram, cada uma, $9,1 \%$ da amostra total. Além disso, os internos com 28 ou 32 anos prevaleceram em 5,7\%, cada. Já os internos com 29, 35, 36 ou 37 anos, estiveram presentes numa porcentagem de 4,5 .

No intervalo de 19 a 29 anos, foram identificados 25 indivíduos. Nesse grupo, a idade de 28 anos foi a mais prevalente, com 5 pessoas. Além disso, foi identificado apenas um paciente acima de 60 anos, representando 1,1\% da amostra total.

Em relação ao período de internação, 13,6\% dos entrevistados estavam há 30 dias, 6,8\% correspondiam a 60 dias, 90 dias, 150 dias, 180 dias e 210 dias, cada, 8\% estavam há 120 dias internados. O período máximo de internação foi de 730 dias para um único interno e teve apenas um interno com um dia de internação. 


\section{Instrumento}

Foi utilizado um questionário que iniciava com duas questões de evocação a respeito do álcool e do crack, seguidas de questões gerais tais como sexo, idade, tempo de internação e contato com familiares. Em seguida, apresentava perguntas sobre tipo de adicção para enfim questionar sobre as práticas utilizadas para conseguir recursos para o uso de drogas. Todas as perguntas eram fechadas.

\section{Procedimento}

Os participantes foram abordados e solicitados a responder o instrumento para um entrevistador individualmente, em salas cedidas pela instituição. Inicialmente, o entrevistador apresentava a pesquisa e preenchia o termo de consentimento livre esclarecido, para em seguida prosseguir com as perguntas do questionário.

\section{Resultados e discussão}

\section{Perfil de drogadição dos moradores de rua}

Esses dados serão analisados a partir da hipótese principal desse trabalho que parte da afirmação que existem três perfis de drogaditos entre os homens de rua: os dependentes de álcool, os dependentes de crack e os polidrogaditos. Nesse sentido, o questionário planejado e aplicado nesse estudo, tentou identificar qual é a droga que os participantes consideram que são adictos, através de três perguntas: sobre a droga que causa abstinência, que o participante não pode ficar sem; a droga de hábito de uso, que o participante utiliza com frequência; e a droga de vício, que o participante se reconhece enquanto viciado.

\begin{tabular}{|c|c|c|c|c|c|c|}
\hline \multirow[t]{2}{*}{ Droga } & \multicolumn{2}{|c|}{ Droga de abstinência } & \multicolumn{2}{|c|}{ Droga de uso habitual } & \multicolumn{2}{|c|}{ Droga de vício } \\
\hline & $f$ & $\%$ & $f$ & $\%$ & $f$ & $\%$ \\
\hline Álcool & 23 & 26,7 & 11 & 12,6 & 17 & 19,5 \\
\hline Crack & 20 & 23,3 & 9 & 10,3 & 17 & 19,5 \\
\hline Cocaína & 3 & 3,5 & 3 & 3,4 & 4 & 4,6 \\
\hline Maconha & 4 & 4,7 & 5 & 5,7 & 2 & 2,3 \\
\hline Outras drogas & 2 & 2,3 & 0 & 0 & 3 & 3,4 \\
\hline Álcool crack & 7 & 8,1 & 9 & 10,3 & 5 & 5,7 \\
\hline Álcool crack e outras & 6 & 7,0 & 24 & 27,3 & 4 & 4,6 \\
\hline Crack e outras & 12 & 14,0 & 12 & 13,8 & 4 & 4,6 \\
\hline Álcool e outras & 6 & 7,0 & 11 & 12,6 & 7 & 8,0 \\
\hline Cocaína, maconha e outras & 3 & 3,5 & 3 & 3,4 & 2 & 2,3 \\
\hline Nenhuma droga & 0 & 0 & 0 & 0 & 22 & 25,3 \\
\hline Total & 86 & 100 & 87 & 100 & 65 & 100 \\
\hline
\end{tabular}


A primeira pergunta - No tempo em que você vivia na rua, qual é a droga que você não podia ficar sem? - foi a mais eficiente em demonstrar qual a droga que os participantes se consideram adictos, pois houve maior número de participantes que escolheram apenas uma opção, demonstrando que eles podiam identificar qual é a droga de adicção. $O$ álcool foi a mais citada $(26,6 \%)$, seguido do crack $(23,3 \%)$, confirmando parcialmente a hipótese inicial. Esse dado pode ser explicado pela acessibilidade dessas drogas. Segundo a Secretaria Nacional de Políticas sobre Drogas (Brasil, 2010), o crack é a droga comercializada no país, pelo preço mais acessível, sendo, portanto, a mais barata. $O$ álcool além de ter um preço acessível, é legalizado e aceito socialmente, estando disponível em vários tipos de comércio. A maconha e a cocaína, pelo contrário, são drogas mais elitizadas e mais caras. Nesse sentido, a maconha foi citada numa porcentagem de $4,7 \%$ e a cocaína foi a droga menos referida (3,5\%), pois provavelmente é a menos acessível delas.

Alguns participantes marcaram mais de uma opção, caracterizando uma polidrogadição, sendo a mais comum crack e outras drogas (14\%), álcool e crack (8\%), álcool, crack e outras drogas (7\%), álcool e outras drogas (7\%) e com menor frequência cocaína, maconha e outras drogas (3,5\%). Somando os que marcaram mais de uma opção, podemos afirmar que 39,6\% parecem sentir abstinência por mais de um tipo de droga.

Em pesquisa qualitativa foi observado que os adictos de crack utilizam outras drogas como paliativos para aliviar os efeitos de pânico vivido durante o efeito excitatório da mesma (Spadoni et al., 2014). Nesse sentido, se somarmos as porcentagens de todas as opções de polidrogadição que incluem o crack, obtemos $29 \%$ dos participantes, sugerindo que o crack seja a principal adicção da conduta de polidrogadição dessa população.

A segunda pergunta que se destinava a identificar a adicção dos participantes - Quais drogas você tinha o hábito de utilizar com frequência? -possui um padrão de resposta semelhante, embora com porcentagens menores. O álcool é a droga que os entrevistados declaram que mais usavam (12,6\%), seguido pelo crack (10,3\%), enquanto a maconha $(5,7 \%)$ e a cocaína $(3,4 \%)$ eram utilizadas com menor frequência. Apesar das porcentagens serem menores, o padrão da resposta é o mesmo, e reafirma a preponderância do uso do álcool e crack entre os participantes. Nesta pergunta, no entanto, os participantes polidrogaditos relatam ter o hábito de utilizar álcool, crack e outras drogas com maior frequência $(27,6 \%)$, crack e outras drogas (13,8\%), álcool e outras drogas (12,6\%), álcool e crack (10\%), e cocaína, maconha e outras drogas (3,4\%). Somando as porcentagens acima, observamos que $67,4 \%$ dos participantes afirmam utilizar mais de um tipo de droga com frequência sendo que as opções mais frequentes de poliuso, também, se referem a álcool, crack e outras drogas, sendo a cocaína e maconha e outras, as opções menos frequentes.

Esses dados sugerem que os participantes fizeram uma diferença entre a droga de abstinência e a droga de uso habitual, pois quando são perguntados sobre a droga que não conseguem ficar sem ela, as respostas com uma única opção são mais frequentes, sendo as mais comuns o crack e o álcool. No entanto, quando perguntados sobre a droga que utilizam habitualmente, o padrão de respostas mais frequente são aquelas que citam mais de uma droga. Isto significa que alguns deles fazem diferença e notam que apesar de sentirem a abstinência de uma droga, eles possuem o habito de utilizar várias delas, indicando que a polidrogadição é uma prática social entre os diversos grupos de drogaditos. 
A terceira pergunta - Você se considera viciado em alguma droga? - também demonstra a preponderância do álcool e do crack. Dos entrevistados, 19,5\% se consideram viciados em crack, e a mesma quantidade se considera viciada em álcool. A maconha é a que menos foi relacionada ao vício (2,3\%), talvez pela ideia do senso comum de que a maconha não vicia, seguida pela cocaína (4,6\%).

Percebe-se que o padrão de respostas se modifica, visto que álcool e droga se equiparam, enquanto que a porcentagem de quem se considera viciado em maconha é menor do que em cocaína. Os participantes que marcaram mais de uma opção são os que marcaram álcool e outras drogas (8\%), álcool e crack (5,7\%), álcool, crack e outras drogas $(4,6 \%)$, crack e outras drogas $(4,6 \%)$ e por fim cocaína, maconha e outras drogas $(2,3 \%)$. Vinte e cinco por cento $(25,2 \%)$ dos participantes se consideram viciados em mais de uma droga, confirmando novamente que eles fazem uma diferença entre as drogas que causam abstinência, nas quais eles se sentem viciados, e as drogas que eles utilizam com frequência.

A repetição do padrão da primeira pergunta permite confirmar que o álcool e o crack são as drogas mais utilizadas, por isso, perguntamos a eles o quanto eles acham que os alcoolistas se comportam diferente dos usuários de outras drogas, numa nota de 1 a 5 , sendo 1 relacionado a nenhuma diferença e 5 correspondentes a uma grande diferença. $A$ maioria parece perceber que existe uma diferença entre esses dois grupos, pois $60,5 \%$ deles deram nota 5 e apenas 15,1\% deram nota 1, o que fez que a média fosse 3,9651 (DP= 1,51423). Esse dado demonstra que os participantes possuem crenças de que há diferenças entre as práticas sociais dos dependentes do álcool e dos dependentes das demais drogas.

As diferenças de perfil entre os alcoolistas e outras dependências foram analisadas a partir de alguns testes estatísticos, no que se refere a faixa etária, meios de conseguir a droga, e práticas antinormativas como roubo e tráfico. Utilizamos a questão Qual a droga que você se considera viciado? e separamos os participantes em grupos: dependentes declarados de crack, de álcool, de crack e álcool, e de outras drogas.

Fizemos um test $t, t(17)=3,978, p<0,001$ que confirmou que os dependentes em crack com média de idade de 31,1111 anos ( $d p=4,63857)$, são mais jovens que os dependentes de álcool cuja a média de idade é de 42,70 ( $d p=11,12181)$. Outro test $t, t(17)=3,514, p<0,001$, confirma que se declaram viciados em álcool são mais velhos que os que se declaram viciados em mais de uma droga cuja a média de idade é 33,0943 ( $d p=9,424)$.

Com relação ao contato com familiares, $74 \%$ dos pacientes mantém contato com duas ou mais pessoas da família, demonstrando que ainda mantém vínculos familiares. A categoria outros $(15,6 \%)$ foi a mais citada, seguido pela mãe $(6,5 \%)$ e pelo pai $(2,6 \%)$. 0 contato com os progenitores é raro. Os usuários de crack $(11,1 \%)$ e álcool (3\%) são os que relatam ter contato com a mãe. Apenas um usuário de crack e álcool relatou contato com o pai (3\%). Os demais usuários mantêm contato com outras pessoas da família.

Em resumo, os dados deste estudo parecem demonstrar que existem três perfis, ou grupos sociais, distintos entre os moradores de rua. Em primeiro lugar os alcoolistas, que se caracterizam por ser mais velhos e manterem menos vínculos familiares com os pais; em segundo lugar os adictos de crack que são mais jovens sendo que alguns mantêm contato com mãe; e em terceiro lugar os polidrogaditos que também são mais jovens e mantém contatos com outras pessoas da família que não os pais. 


\section{Práticas sociais antinormativas entre alcoolistas, dependentes de crack e polidrogaditos}

Para comprar drogas, o usuário de álcool alega que, antes de se internar, trabalhava regularmente (40\%) ou prestava serviços para as pessoas (5\%). Quarenta e cinco por cento dos dependentes em álcool marcou mais de uma opção e afirmou que trabalhava e fazia outras coisas, prestava serviços e/ou traficava, roubava ou se prostituía (45\%). Apenas $5 \%$ afirmou que não trabalhava e conseguia dinheiro apenas por outros meios, como trafico, roubo, prostituição e prestação de serviços. Somando os dois últimos itens, temos que $50 \%$ dos participantes afirmam que conseguiam a droga através de práticas antinormativas.

O usuário de crack 5,6\% prestava serviços para as pessoas para comprar drogas. $E$ $61,1 \%$ afirmavam que trabalhavam e faziam outras coisas como prestação de serviços, roubo e prostituição. No entanto, $27,8 \%$ não trabalhavam e conseguiam dinheiro por outros meios, inclusive trafico, roubo, prostituição e prestação de serviços. Se somarmos os últimos dois itens, teremos que $88,9 \%$ dos dependentes de crack afirmam conseguir a droga através de práticas antinormativas. Destacamos ainda que nesse grupo não apareceu pessoas que afirmaram apenas trabalhar.

Os que se consideraram viciados em álcool e crack, $27,3 \%$ relatou trabalhar regularmente. E 9,1\% prestava serviços, 3\% traficava drogas, 39,4\% trabalhava e fazia outras coisas como prestação de serviços, trafico, roubo e prostituição. Cerca de $18,2 \%$ não trabalhava e conseguia dinheiro por outros meios como prestação de serviços, trafico, roubo e prostituição. Somando os três últimos itens anteriores, temos que $60,6 \%$ afirmam conseguir a droga através de práticas antinormativas. E 3\% obtinha dinheiro por outros meios.

Os viciados em outras drogas 33,3\% trabalhavam regularmente, $50 \%$ trabalhava e fazia outras coisas inclusive roubar, traficar e se prostituir. E 16,7\% não trabalhava e conseguia dinheiro por meio de prestação de serviços, mas também por roubo, tráfico e prostituição, totalizando $76,7 \%$ de participantes que afirmam praticar práticas antinormativas a fim de conseguir a droga.

Pode causar estranheza ao senso comum, o fato de muitos afirmarem que trabalhava regularmente enquanto moravam na rua. No entanto, em 2008, dados da Pesquisa Nacional sobre a população em situação de rua mostravam que $70,9 \%$ exerciam alguma atividade remunerada. Destas atividades destacavam-se: catador de materiais recicláveis $(27,5 \%)$, flanelinha (14,1\%), construção civil (6,3\%), limpeza $(4,2 \%)$ e carregador/estivador $(3,1 \%)$. Pediam dinheiro como principal meio para a sobrevivência apenas $15,7 \%$ das pessoas (Brasil, 2008). Essa porcentagem de moradores de rua que trabalham regularmente é bem menor no nosso estudo do que na pesquisa nacional acima citada. Podemos pensar em duas explicações possíveis para este fato: primeiramente que nossa amostra é regional e a da pesquisa de 2008 é nacional; e em segundo lugar, pode ter havido uma mudança nas práticas dessa população.

Esses resultados estabelecem uma diferença entre os adictos de álcool, de crack e os polidrogaditos, indicando que os alcoolistas afirmam com maior frequência que trabalhavam regularmente (40\%) sendo que nenhum adicto de crack afirmou o mesmo. Em contrapartida, tanto os usuários de álcool e crack $(27,3 \%)$ quanto os de outras drogas $(33,3 \%)$ também afirmaram trabalhar regularmente. 
No mesmo sentido, os usuários de crack (88\%) foram os que afirmaram utilizar de meios contranormativos com maior frequência, seguidos dos adictos de outras drogas $(76,7 \%)$, dos adictos de álcool e crack $(60,6 \%)$, sendo os alcoolistas os que declaram com menor frequência a utilização de meios contranormativos para obter as drogas (50\%). Se considerarmos os que se declaram adictos de álcool e crack juntamente com os adictos de outras drogas enquanto polidrogaditos, podemos afirmar que, no que tange as práticas contranormativas, os alcoolistas são menos adeptos que os demais, e os adictos de crack são os mais adeptos de tais práticas.

Em seguida fizemos pergunta especificas a respeito do roubo, sendo que $20 \%$ dos alcoolistas declararam que sim; $72,2 \%$ dos adictos em crack também afirmaram que já roubaram para comprar drogas e $54,5 \%$ dos viciados nas duas drogas também já roubaram para conseguir dinheiro para comprar drogas. Dos adictos em outras drogas $66,7 \%$ também já tiveram este comportamento.

Através desses dados, pode-se perceber que os alcoolistas parecem menos adeptos de práticas antinormativas para conseguir custear as drogas. Enquanto que as demais drogas são ilegais e parecem estar mais associadas a práticas ilegais. O fato de já estarem na ilegalidade devido ao uso de drogas ilegais, pode influenciá-los a aceitar também outras práticas ilegais como roubar e traficar.

Esses dados demonstram que os dependentes de crack além de serem mais jovens do que os dependentes de álcool, afirmam com maior frequência, que não trabalhavam regularmente quando estavam na rua e que se utilizavam de práticas antinormativas tais como roubo, tráfico com maior frequência para conseguir a droga. Os que se consideram viciados em ambas as drogas, ou em outras drogas também são mais jovens e praticam mais práticas antinormativas que os alcoolistas e podem caracterizar um grupo social que se identifica pela polidrogadição.

Esses dados em conjunto, permitem formular a hipótese de que o perfil de dependência e de práticas do morador de rua está se transformando, visto que no passado predominava os alcoolistas que vêm sendo substituído pelos adictos do crack e os polidrogaditos, que caracteriza uma população mais jovem, e mais vulnerável à ilegalidade.

Para finalizar, vamos apresentar o resultado da questão de evocação sobre o álcool e o crack, que foi apresentada aos participantes como a primeira questão a ser respondida. Os resultados permitem complementar as diferenças entre o álcool e o crack, compartilhadas pelo senso comum dos moradores de rua.

\section{Representações sociais do álcool e do crack}

Introduzimos no questionário uma pergunta clássica nos estudos de representações sociais conhecida como evocação simples a respeito do álcool e crack. O objetivo dessas perguntas foi investigar quais os conteúdos das representações dessas drogas, se elas se diferenciam e no que se diferem. Nesse caso, as respostas foram tratadas sem considerar o tipo de drogadição dos participantes, visto que o objetivo é analisar as representações sociais que circulam entre eles e como eles diferenciam o crack do álcool.

A técnica de evocação simples tem sido empregada para identificar os possíveis componentes do núcleo central ou da periferia de uma representação social. São solicitadas 
aos participantes as três primeiras palavras ou expressões lembradas após o conhecimento de um termo indutor. Vergès (1992) propôs que sua análise fosse feita através do cruzamento da frequência das respostas e da rapidez com que foram proferidas, produzindo um quadro composto por quatro casas. Os itens com maior frequência e menor média de ordem de citação (casa 1) podem ser elementos que caracterizam o núcleo central de uma representação. Os itens com frequência baixa, mas com alta média de ordem de citação podem caracterizar os elementos periféricos (casa 4). E os itens das duas casas restantes são considerados uma zona de instabilidade, que possivelmente estão em processo de mudança.

O valor 2,0 foi adotado como referencial de média de ordem de citação, por ser o valor médio, já que foi pedido aos participantes três respostas. Como frequência mínima, definiu-se o valor de duas respostas, sendo excluídos, portanto, os itens citados menos de duas vezes. Definiu-se também, como frequência média, um valor equivalente à $10 \%$ do número total de participantes, o que significa que os itens considerados com alta frequência foram citados por pelo menos $10 \%$ da amostra. Esse valor foi definido com o objetivo de reter, na primeira casa, apenas os elementos com o maior nível de consenso.

\begin{tabular}{c|c|c|c|c|c|c}
\hline & $>2$ & Frequência & $\begin{array}{c}\text { Ordem } \\
\text { citação }\end{array}$ & $\leq 2$ & Frequência & $\begin{array}{c}\text { Ordem } \\
\text { citação }\end{array}$ \\
\hline \multirow{3}{*}{$5 \geq$} & Prazer & 12 & 1,7 & Angústia & 12 & 2,2 \\
& Medo & 15 & 1,9 & Arrependimento & 9 & 2,2 \\
& Tristeza & 14 & 1,8 & - & - & - \\
& Raiva & 8 & 1,8 & - & - & - \\
& Destruição & 10 & 1,6 & - & - & - \\
& Sofrimento & 9 & 1,9 & - & - & - \\
& Aversão & 12 & 1,5 & - & 5 & 2,2 \\
& Sentimentos & 5 & 1,6 & Perda & - & - \\
$7 \geq$ & negativos & & & & - & - \\
& Vontade & 6 & 1,5 & - & - & - \\
\hline & Alegria & 6 & 1,7 & - & - & - \\
& Euforia & 5 & 1,8 & - & & \\
\hline
\end{tabular}

Figura 1 - Representação social do crack

Em relação ao uso do crack, apareceram como elementos centrais, isto é, o que possui significância consistente nas representações sociais, as palavras "medo", "tristeza", "destruição", "raiva", "sofrimento" e "aversão". Dessa forma, percebe-se que essas palavras remetem a sentimentos desprazerosos em relação ao uso da droga, sendo assim, sentimentos negativos.

Contudo, a palavra prazer é enfatizada com grande frequência, levando a hipótese que o efeito agradável muitas vezes se sobrepõe ou alivia os sentimentos negativos, levando-os ao uso contínuo da droga.

Porquanto, segundo Galduróz, Noto e Carlini (1997) o abuso do crack acontece devido a sensação agradável gerada a princípio de seu consumo, todavia, os efeitos a longo prazo acarretam em deterioração físicas e psicológicas; e com isso, a necessidade de procura da droga é cada vez maior, com a intenção de voltar a sentir o mesmo bem-estar vivenciado das primeiras vezes. 
A periferia das representações sociais do crack foi composta pela palavra "perda", possivelmente relacionada a tudo que eles perderam com o uso da droga até chegarem a morar na rua, que apesar de ser menos evocada em primeira mão pelos sujeitos da pesquisa, complementa os sentimentos negativos do núcleo central das representações sociais do crack. (Machado \& Aniceto, 2010).

Por fim, na zona de instabilidade, apareceram fortemente as palavras "alegria", "euforia" e "vontade". Em resumo, as sensações agradáveis aparecem com menor importância que as sensações desagradáveis na estruturação dos conteúdos da representação social do crack, indicando que é uma droga associada ao sofrimento nas ideias do senso comum dos participantes, ao contrário do álcool, como veremos a seguir.

\begin{tabular}{c|c|c|c|c|c|c}
\hline & $>2$ & Frequência & $\begin{array}{c}\text { Ordem } \\
\text { citação }\end{array}$ & $\leq 2$ & Frequência & $\begin{array}{c}\text { Ordem } \\
\text { citação }\end{array}$ \\
\hline \multirow{3}{*}{$5 \geq$} & Prazer & 12 & 1,7 & Angústia & 12 & 2,2 \\
& Medo & 15 & 1,9 & Arrependimento & 9 & 2,2 \\
& Tristeza & 14 & 1,8 & - & - & - \\
& Raiva & 8 & 1,8 & - & - & - \\
& Destruição & 10 & 1,6 & - & - & - \\
& Sofrimento & 9 & 1,9 & - & - & - \\
& Aversão & 12 & 1,5 & - & 5 & 2,2 \\
& Sentimentos & 5 & 1,6 & Perda & - & - \\
$7 \geq$ & negativos & & & & - & - \\
& Vontade & 6 & 1,5 & - & - & - \\
\hline
\end{tabular}

Figura 2 - Representação Social do Álcool

O núcleo central das representações sociais do álcool foi expresso pelas palavras "prazer" e "alegria", tendo assim prevalência de sentimentos agradáveis que podem esta relacionados a aceitação e aprovação do seu uso na sociedade.

Para Michel (2002), o álcool é uma droga subestimada, pois a nossa cultura encara-a como fonte integrante de uma vida "normal". Assim, ela integra praticamente todos os ambientes e situações: aparece nos finais de semana, como momento de prazer e lazer, associada a desportos, viagens e trabalho.

Contudo, a frequência da resposta tristeza também foi elevada, revelando que, o uso do álcool apesar de proporcionar bem-estar momentâneo pode manifestar uma tristeza préexistente, ou até mesmo provocá-la. Segundo Oliveira e Nappo (2008), o alcoolismo é uma doença que pode prejudicar a pessoa que o consome e não só, pois muitas vezes pode também provocar sentimentos de angustia e tristeza. Esses sentimentos são originados por frustrações e tensões que, com o consumo excessivo de álcool, acabam por se manifestar. A zona periférica foi composta pelas expressões "vontade" e "depressão" levando a hipótese que o uso do álcool possui certa dicotomia nas representações sociais e não são facilmente expressas no discurso diário dessa população. Ainda para Oliveira e Nappo (2008), socialmente, o alcoolismo determina uma enorme ambiguidade: tolerado e mais do que tolerado, é estruturante do desenvolvimento psicossocial e individual, mesmo apesar do reconhecido risco que acarreta em termos de saúde no seu conceito mais lato, ou seja, o de bem-estar físico, psíquico e social. Assim, é possível que coexistam, socialmente, uma gama 
de apelos ao seu consumo (dos mais explícitos aos mais sutis), com uma permanente chamada de atenção para os seus riscos da parte dos sistemas de consumo. Portanto, ao mesmo tempo em que existe o desejo de consumo, há também uma via de mão dupla, na qual a melancolia pode gerar o vício, ou ser motivada por ele.

A periferia das representações foi marcada pela palavra "destruição", que pode estar relacionada ao distanciamento dos laços familiares e inúmeras separações que vivenciam; contudo, isso pode ser considerado como consequência gerada pelo abuso do álcool, mas que não se apresenta no núcleo central. Tal como em qualquer outro ser humano, também, o comportamento do dependente vai influenciar de forma mais intensa e primeiramente, aqueles que dele estão mais próximos. De fato, a família destes indivíduos sofre muitas vezes, as consequências do abuso do álcool de um dos seus membros e, aqui, é necessário frisar que estas consequências afetam não apenas o convívio familiar, mas também a dimensão econômica, social, afetiva, entre outras. (Oliveira \& Nappo, 2008).

Em resumo, as representações sociais destas duas drogas confirmam que a drogadição relativas a elas é vista de forma diferenciada. Enquanto que o álcool é associado predominantemente a sentimentos prazerosos, seus adictos são considerados diferentes dos demais, declarando com maior frequência que trabalhavam regularmente enquanto estavam nas ruas; e declarando com menor frequência, que os demais drogaditos, que eram adeptos de práticas antinormativas. Percebeu-se ainda que eles são mais velhos e talvez por isso já se desfizeram de mais laços familiares.

Por outro lado, o crack tem uma representação social marcada pelos sentimentos desprazerosos e seus adictos, assim como os polidrogaditos, declaram com menor frequência que trabalhavam antes de serem internados; e ainda declaram com maior frequência que roubavam e eram adeptos de práticas antinormativas para conseguir dinheiro ou a droga. Foi constatado ainda que essa população é mais jovem e mantém vínculos com alguns familiares, embora os vínculos parentais se apresentem como bem enfraquecidos.

\section{Conclusão}

A partir de 2004, o debate a respeito de políticas públicas voltadas especificamente para a população em situação de rua foi intensificado procurando abranger as peculiaridades que caracterizam essa população. Nesse sentido, esse estudo teve como objetivo conhecer características específicas deste grupo a fim de munir de informações os executores dessas políticas públicas.

Nesse sentido, a abordagem do artigo não é um levantamento epidemiológico clássico, e sim um estudo que parte das ideias do senso comum dos próprios moradores de rua, que estão sendo cuidados por uma instituição filantrópica, e concordaram em participar com o intuito de ajudar a equipe pesquisadora a compreender as ideias que circulam entre eles principalmente no que tange as práticas sociais prescritas por suas representações.

A partir da observação inicial do médico da instituição, foi possível estabelecer uma hipótese inicial que direcionou os trabalhos e foi confirmada. Para os moradores de rua, os alcoolistas se diferenciam muito, em termos de práticas, dos demais drogaditos. 
Através dos dados, foi possível observar que os participantes que se consideram polidrogaditos e adictos de crack são mais adeptos de práticas antinormativas tais como roubar e traficar, além, de serem mais jovens.

Além disso, a representação social do álcool parece ser associada a alegria e ao prazer enquanto que a representação social do crack é marcadamente negativa, e inclui componentes como tristeza, aversão e sofrimento.

Sugerimos que outros estudos sejam conduzidos a fim de caracterizar as peculiaridades de cada um desses grupos sociais que compõem a população dos moradores de rua.

São frequentes e numerosas as tentativas de mudar as práticas e as normas dos grupos sociais através de políticas públicas de saúde, principalmente no âmbito da promoção e prevenção.

Segundo Spadoni et al. (2012) as ações das políticas públicas, ou de qualquer pretensão educativa por parte do estado, tem o impacto de informações desconhecidas e contraditórias para grupos da população criando um conflito entre as normas estatais e as normas grupais. Nesse caso, a tendência é prevalecer às normas do grupo, pois estas possuem maior poder de pressão porque o indivíduo convive com o grupo sendo que o estado é mais distante (Spadoni, 2016).

Deste fato surge a necessidade de se conhecer as normas e práticas desta população, pois aquilo que é contranormativo para outros grupos da sociedade, parece não ser para eles, em determinadas situações.

Perez (1999, p. 626) definiu as normas como um conjunto de comportamentos e de reações que um grupo social aprova ou desaprova e que, portanto, ele (o grupo) espera que seja regularmente adotado ou evitado. Práticas de risco são ações realizadas por pessoas que aumentam as chances de consequências adversas para seu funcionamento e desenvolvimento psicológico ou social, ou ainda que favoreçam o desencadeamento ou agravamento de doenças (Hutz \& Koller, 1996).

No caso dos moradores de ruas, vários esforços são feitos através e políticas públicas que visam protege-los de sua vulnerabilidade, sendo que muitos desses esforços incluem tentativas de mudança de práticas de risco. Esses esforços podem ser direcionados a partir do conhecimento dos grupos sociais dessa população e de suas normas de conduta.

\section{Referências}

Abric, J. C. (1994). Les représentations sociales: aspects théoriques. In: J.C. Abric. Pratiques sociales et représentations (p. 11-36). Paris, Presses Universitaires de France.

Booth R. E., Kwiatkowski, C.F. \& Chitwood D. D. (2000). Sex related HIV risk behaviors: differential risks among injection drug users, crack smokers, and injection drug users who smoke crack. Drug Alcohol Depend, 58(3), 219-26.

Botti, N. C. L., Castro, C. G. de, Silva, A. K., Silva, M. F. da, Oliveira, L. C. de, Castro, A. C. H. O. A. de \& Fonseca, L. L. K. (2010). Alcohol use pattern among homeless adult men in Belo Horizonte. SMAD, Rev.

Eletrônica Saúde Mental Álcool Drog. (Ed. port.), Ribeirão Preto, 6(n. spe).

Brasil (2008). Pesquisa Nacional sobre a População em Situação de Rua. Ministério do Desenvolvimento Social e Combate à Fome. Secretaria de Avaliação e Gestão da Informação. Brasília: MDS. 
Brasil. (2010). Drogas: cartilha sobre maconha, cocaína e inalantes. Secretaria Nacional de Políticas sobre Drogas. Brasília: Presidência da República.

Costa, A. P. M. (2005). População em situação de rua: contextualização e caracterização. Revista Virtual Textos \& Contextos, 4(IV), dez.

Cruza, M. S., Vargens, B, R. W. \& Ramôac, M. L. (2010). Crack: Uma abordagem multidisciplinar. Presidência da República - SENAD.

Duailibi, L. B., Ribeiro, M. \& Laranjeira, R. (2013). Profile of cocaine and crack users in Brazil. Cad. Saúde Pública, 24(4), 545-557.

Ferreira, F. P. M. (2005). População em situação de rua, vidas privadas em espaços públicos: o caso de Belo Horizonte 1998- 2005. Belo Horizonte. Disponível em: http://www.cedeplar.ufmg.br. Acesso em: 31 mai 2012.

Figueiredo, R. (2002). Prevenção ao abuso de drogas em Ações de Saúde e Educação: uma abordagem sócio-cultural e de redução de danos. São Paulo: NEPAIDS-USP.

Galduróz, J. C. F., Noto, A. R., \& Carlini, E. A. (1997). VI Levantamento sobre uso de drogas em estudantes de 1 los e 2 los graus em 10 capitais brasileiras. São Paulo: Universidade Federal de São Paulo.

Hutz, C. S. \& Koller, S. H. (1996). Questões sobre o desenvolvimento de crianças em situação de rua. Universidade Federal do Rio Grande do Sul, Estudos de Psicologia, 2(1), 175-197.

Jodelet, D. (1989). Les représentations sociales, Paris: Presses Universitaires de France.

Lovisi, G.M. (2000). Avaliação de distúrbios mentais em moradores de albergues públicos das cidades do Rio de Janeiro e de Niterói. Tese de Doutorado. Escola Nacional de Saúde Pública/Fiocruz, Rio de Janeiro, RJ.

Machado, L. \& Aniceto, R. (2010). Núcleo central e periferia das representações sociais de ciclos de aprendizagem entre professores. Aval. Pol. públ. Educ., 18(67), 345-364.

Mattos, R. M., Campos, G. M. \& Ferreira, R. F. (2004). Situação de rua e alcoolismo: processos que se determinam mutuamente. BarBarói, 21, 93-118.

Michel, O. R. (2002). Álcool, drogas e alucinações: como tratar. Rio de Janeiro: Editora Revinter.

Moscovici, S. (1978). A representação social da psicanálise. Rio de Janeiro: Zahar.

Noto, A. R., Galduróz, J. C., Nappo, S. A., Fonseca, A. M., Carlini, C. M. A. \& Moura Y.G. (2003). Levantamento nacional sobre uso de drogas entre crianças e adolescentes em situação de rua nas 27 capitais brasileiras - 2003. São Paulo: Secretaria Nacional Antidrogas/Centro Brasileiro de Informações sobre Drogas Psicotrópicas.

Oliveira, L. G. de \& Nappo, S. A. (2008). Caracterização da cultura de crack na cidade de São Paulo: padrão de uso controlado. Rev. Saúde Pública, 42(4), 664-671.

Pechansky F. I., Von Diemen, L. I., Kessler, F. I., Hirakata, V. I. , Metzger, D. I. I. \& Woody G. (2002). Incidência de infecção por HIV entre abusadores de cocaína em Porto Alegre. Rev Bras Psiquiatr, 24(2), 5-25.

Perez, J. (1999). Normes Sociales. Grand Dictionnaire de la Psychologie. Paris: Larousse.

Pousa Júnior, E. F. (2011). Políticas públicas para inclusão social dos moradores em situação de rua. Um resgate por cidadania. Jus Navigandi, 16(2778). Disponível em: <https://jus.com.br/artigos/18448>. Acesso em: 2 jan. 2016.

Rouquette, M-L. (2009). Qu'est-ce que la pensée sociale. In : M-L Rouquette (org). La pensée sociale. Perspectives fondamentales et recherches appliquées. Toulouse : Érès.

Rouquette, M. L. (1973). La pensée sociale, dans Moscovici. Introduction à la psychologie sociale (p. 299327). Paris: Larousse.

São Paulo (Cidade). (2015). Censo da população em situação de rua da cidade de São Paulo, 2015. Prefeitura Municipal. Secretaria Municipal de Assistência e Desenvolvimento Social. São Paulo: FIPE.

Snow, D. \& Anderson, L. (1998). Desafortunados: um estudo sobre o povo da rua. Petrópolis: Vozes. 
Spadoni, L., Gambi-Mass, D. \& Torres, A. R. (2012). Psychologie politique et législation: normes, representations sociales et pratiques du nom du père. Bulletin de Psychologie, 2(518), 141-149.

Spadoni, L., Machado Junior, C. P., Silva Neto, C, Carvalho, J., Goçalves, C., Brunini, S., Esperidião, E. \& Sousa, J. M. (2014). O medo e a Polidrogadição em Moradores de Rua Usuários de Crack. Atas CIAIQ2014. Investigação Qualitativa em Ciências Sociais. Vol. 3.

Spadoni, L. (2016). Psicologia realmente aplicada ao Direito. 2 ed. São Paulo: LTR.

Varanda, W. \& Adorno, R. C. F. (2004). Descartáveis urbanos: discutindo a complexidade da população de rua e o desafio para políticas de saúde. Saudesoc, 13(1), 56-69.

Vergés, P. (1992). L'évocation de l'argent: Une méthode pour la définition du noyau central d'une représentation. Bulletin de Psychologie, 405, 203-209.

Vieira, M. A. C. (1995). Pesquisa sobre o perfil da população de rua de São Paulo. In: C.M.M. Rosa (org). População de rua: Brasil-Canadá (p. 42-45). São Paulo: Hucitec. 